\section{Heat Transfer Characteristics of GGBS Concrete in Fire}

\section{Ted McKenna}

Department of Civil, Structural and Environmental Engineering, Cork Institute of Technology, Bishopstown, Cork, Ireland

\section{Mark G. Richardson*}

2 School of Civil, Structural and Environmental Engineering, University College Dublin, Belfield, Dublin 4, Ireland

\section{Brian O'Rourke}

Department of Civil, Structural and Environmental Engineering, Cork Institute of Technology, Bishopstown, Cork, Ireland

*Corresponding author: mark.richardson@ucd.ie

$\Gamma$ Grossef $h t t p: / / d x . d o i . o r g / 10.5755 /$ j01.sace.8.3.7457

Partial replacement of high clinker content cements by Ground Granulated Blastfurnace Slag (GGBS) can reduce the carbon footprint of concrete, with consequent benefits in respect of sustainable construction. Furthermore a state-of-the-art report indicated that use of GGBS as a binder replacement may increase the fire resistance of concrete. If so this could lead to thinner sections in fire compartment elements, especially non-loadbearing walls, leading to further gains in respect of sustainable development. Concrete is considered an effective material in protecting against the detrimental effects of fire in structures. However, exposure to high temperatures can degrade concrete performance. Fire resistance performance is typically defined relative to three failure criteria: load bearing resistance (R), insulation (I) and integrity (E). Heat transfer is a critical element of insulation and integrity performance.

An experimental programme was developed to examine the potential beneficial influence of GGBS on fire resistance by examining the heat transfer performance of concrete, with and without GGBS. Test panels of concrete were subjected to heating to high temperatures. The panels included either limestone or sandstone aggregate, and a binder content of either CEM ॥/A-L only or a CEM ॥/A-L and GGBS combination at a cement replacement level of $70 \%$. Concrete panels were heated in accordance with the standard fire curve of Eurocode 2.

It was found that the heat transfer behaviour was in line with published data in the Eurocode for structural fire design. When exposed to elevated temperatures, such as those experienced in a fire situation, the performance of concrete containing GGBS exhibited a marginally lower rate of heat transfer than that of CEM II/A-L concrete. This resulted in a marginal improvement in the separating function (EI) performance. The marginally lower transfer of heat exhibited by GGBS concrete improved performance in terms of El, such that a $5 \%$ reduction in the thickness of reinforced concrete separating elements could be considered. In addition, increased resistance to the effects of actions on a member, designed in accordance with the $500^{\circ} \mathrm{C}$ isotherm 'simplified' method detailed in Eurocode 2, demonstrated a potential increased resistance of up to $10 \%$.

KEYWORDS: concrete, fire, GGBS, heat transfer
JSACE $3 / 8$

Heat Transfer

Characteristics of GGBS Concrete in

Fire

Received

2014/06/28

Accepted after

revision

2014/09/11

\section{ktu \\ 1922}

Journal of Sustainable Architecture and Civil Engineering Vol. 3 / No. 8 / 2014 pp. $45-58$ DOI 10.5755/j01.sace.8.3.7457 (C) Kaunas University of Technology 


\section{GGBS and Fire Resistance}

The use of waste byproducts of the steel industry such as Ground Granulated Blastfurnace Slag (GGBS) as replacement for high clinker content cement develops the opportunity for more sustainable buildings. GGBS offers a sustainable replacement for high clinker content cements being used at replacement levels of up to 70\%. GGBS has slow hydraulic activity on its own and is activated by lime (calcium hydroxide) and other alkaline solutions produced during the hydration of cement clinker.

A state-of-the-art review by Aßbrock et al. (2007) highlighted potential beneficial effects of using GGBS as a binder replacement to increase fire resistance of concrete. The report traces such assertions back as far as 1936, in research by G.M. Rustschuk.

\section{Heat Transfer}

Assessment of performance in fire is based on the behaviour of specific elements and is not an evaluation of the reaction of individual component materials. Standard fire exposure test methods are used to determine fire resistance, reflecting the three limit states of load-bearing capacity $(R)$, integrity $(E)$ and insulation (I). Integrity $(E)$ and insulation $(I)$ refer to the ability of an element or system to perform a separating function under fire conditions. Integrity (E) is a measure of ability to resist spread of flame and smoke to the non-exposed side of a separating element. Insulation (I) is a measure of the ability of a separating element to restrict temperature rise on the non-exposed face to acceptable limits. Heat transfer characteristics of a material influence performance in terms of both $\mathrm{E}$ and $\mathrm{I}$.

Transfer of heat should be limited so that neither the unexposed surface nor any material in close proximity to that surface is ignited. The element should also provide a barrier to heat, sufficient to protect people near to it. For all separating elements, except doors and shutters, the performance criterion used to define thermal insulation imposes a limit in respect of the mean temperature rise on the unexposed face to $140^{\circ} \mathrm{C}$ above the initial mean temperature, with the maximum temperature rise at any point limited to $180^{\circ} \mathrm{C}$ above the initial mean temperature.

Two aspects of the assessment of integrity which are influenced by heat transfer are the ignition of a cotton pad and the occurrence of sustained flaming on the unexposed side (i.e. greater than 10 seconds).

\section{Thermal Conductivity}

Thermal conductivity measures the ability of a material to conduct heat and is defined as the ratio of the flux of heat to temperature gradient. The thermal conductivity of concrete depends on its composition including: type of aggregates, hardened cement paste and void content, as well as degree of saturation. Harmathy (1970) reports that the thermal conductivity of cement paste does not vary significantly with increased temperature and it is the aggregates which have the primary influence on the thermal conductivity of concrete.

Khan (2002) concluded that aggregate type significantly influences thermal conductivity. As

Typical Values of Thermal Conductivity of Concrete (Neville, 1995)

\begin{tabular}{c|c|c}
\hline $\begin{array}{c}\text { Type of } \\
\text { aggregate }\end{array}$ & $\begin{array}{c}\text { Wet density } \\
\text { of concrete } \\
\left(\mathrm{kg} / \mathrm{m}^{3}\right)\end{array}$ & $\begin{array}{c}\text { Conductivity } \\
(\mathrm{W} / \mathrm{m} \mathrm{K})\end{array}$ \\
\hline Limestone & 2450 & 3.2 \\
\hline Sandstone & 2400 & 2.9 \\
\hline
\end{tabular}
aggregates typically make up $60-80 \%$ of the volume of concrete the type and volume have an obvious influence on the thermal conductivity. Typical values of conductivity of concrete made with limestone or sandstone aggregates are listed in Table 1 (Neville, 1995). The factors affecting the thermal properties of concrete at ambient temperature and 
applicability to its prediction models were investigated by Khan (2002). It is clear from the results that the thermal conductivity of the aggregate influences the thermal conductivity of the concrete. However, it is worth noting that the magnitude of difference for the aggregates is not replicated in the concretes.

Thermal conductivity values for design purposes may be determined from graphs in I.S. EN 19921-2 (NSAl, 2005), which present lower and upper limits (Figure 1). The lower limit is typically more representative of normal strength concrete manufactured with normal aggregates. Thermal conductivity tends to increase slowly up to between $500 \mathrm{C}$ and $600 \mathrm{C}$, and then decreases sharply as the temperature rises to $1200 \mathrm{C}$ as a result of loss of water from the concrete. It stabilises at temperatures in excess of $1200 \mathrm{C}$ to $1400 \mathrm{C}$ while at $8000 \mathrm{C}$ it is approximately half of the value at 200C (Neville, 1995).

The thermal conductivity of water, while low, is much greater than that of air and hence the degree of saturation of the concrete affects the conductivity. The lower the water/cement ratio of a mix, the higher the conductivity of the resulting hardened concrete. Khan (2002) concluded that thermal conductivity of concrete increased with increased moisture content, with the increase being more significant from dry state to $50 \%$ saturated.

Demirboğa (Demirboga, 2007, Demirboga et al., 2007) investigated the influence of binder type on the thermal conductivity of concrete at ambient temperature and found that the thermal conductivity decreased with increased replacement of Portland cement with fly ash and GGBS respectively. The decrease is more significant for fly ash with a 39\% decrease in thermal conductivity at replacement levels of $70 \%$. The addition of GGBS resulted in a decrease in thermal conductivity of $15 \%$ at replacement levels of $50 \%$ but thereafter appears to remain approximately constant. Based on the research by Demirboğa, the relationship between thermal conductivity of concrete and proportion of fly ash and blastfurnace slag binder replacements is illustrated in Figure 2.

\section{Specific Heat}

Specific heat represents the heat capacity of concrete. Factors affecting specific heat include aggregate type
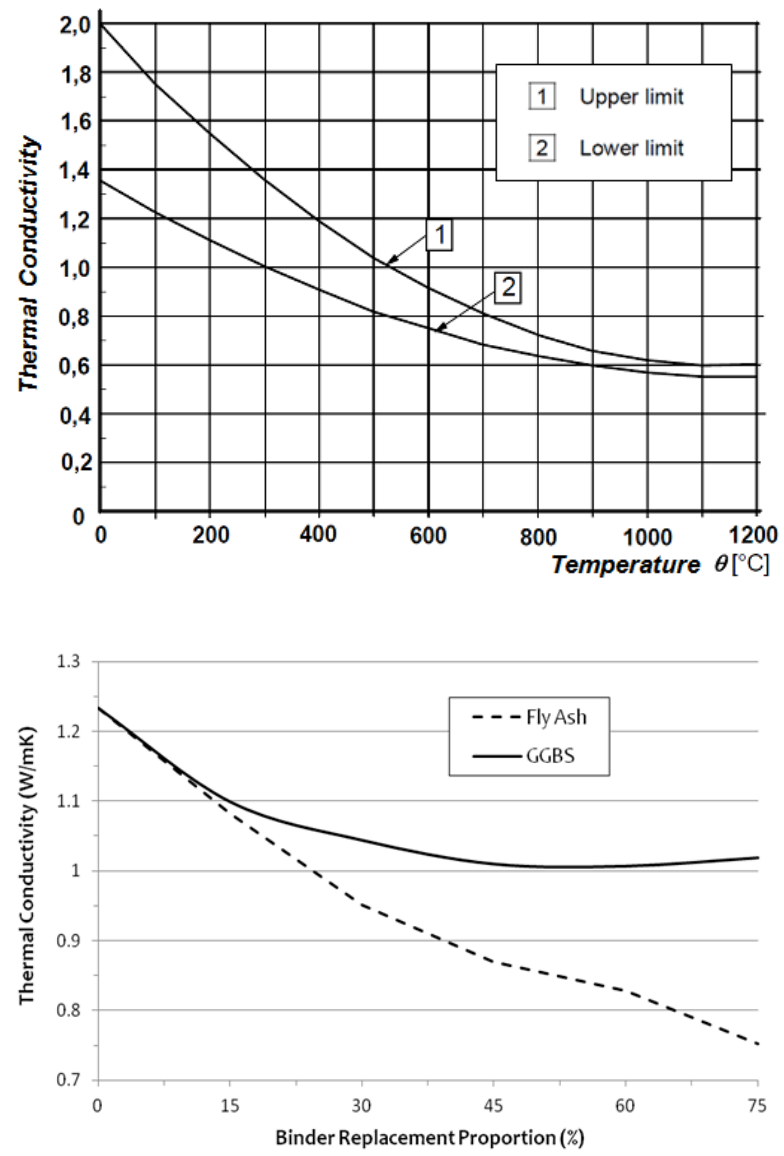

Fig. 2

Relationship between thermal conductivity of concrete and proportion of fly ash and blastfurnace slag binder replacements (Demirboga, 2007)

$c_{\mathrm{p}}(\theta)\left[\mathrm{kJ} / \mathrm{kg}^{\circ} \mathrm{K}\right]$

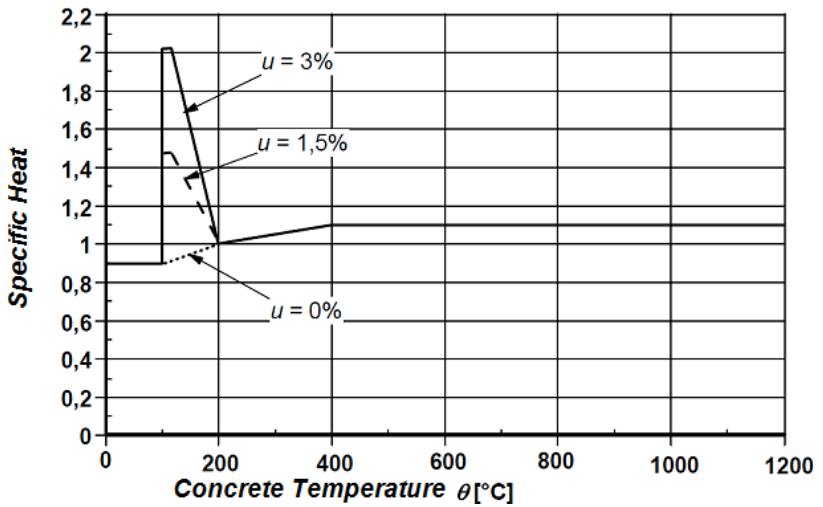

\section{Fig. 3}

Specific heat as function of temperature at three different moisture contents for design in accordance with I.S. EN 1992-1-2 (NSAl, 2005) 
and moisture content of concrete. The values of specific heat for ordinary concrete typically range between 840 and $1170 \mathrm{~J} / \mathrm{kgK}$. Moisture content of the concrete significantly affects the value of specific heat while the mineralogical character of the aggregate is of little influence. Specific heat for fire design should be in accordance with Section 3.3.2 of I.S. EN 1992-1-2. The specific heat at varying concrete temperatures and at three different moisture contents is illustrated in Figure 3. The moisture content $(\mathrm{u})$ is given as a percentage weight for siliceous concrete.

\section{Thermal Diffusivity}

Thermal diffusivity represents the rate at which temperature change within a mass can take place under transient thermal conditions. It is an index of the ability of concrete to undergo temperature change, representing the ratio between the amount of heat transferred by conduction and that stored by the material itself (Bamonte et al., 2008). Thermal diffusivity is related to the conductivity, specific heat and density of a concrete and is determined using Equation 1:

$$
\begin{array}{ll|l}
\text { Thermal Diffusivity, } \alpha=\frac{\lambda}{c_{p} \cdot \rho} & \text { (1) } \quad \begin{array}{l}
\text { where: } \\
\alpha \text { is the Thermal Diffusivity; } \\
\lambda \text { is the Thermal conductivity; } \\
c_{p} \text { is the Specific heat; } \\
\rho \text { is the Density of concrete. }
\end{array}
\end{array}
$$

The measurement of diffusivity consists of determining the relationship between time and the temperature differential between the surface and the interior of a concrete specimen. While thermal diffusivity of concrete is easier to measure experimentally than its three components separately, the thermal conductivity $(\lambda)$ and volumetric specific heat $\left(c_{p} . \rho\right)$ are required to be input separately (FIB, 2007). As moisture content affects diffusivity, the moisture content during testing should be that which exists in the actual structure. The unstable state of concrete under dynamic heating conditions and the time and temperature dependent endothermic and exothermic transformations, influence the measurement of specific heat at a given temperature. Consequently, careful judgement is required for the selection of thermal properties, with varying equipment and procedures in various laboratories around the world giving significantly varying properties for apparently similar concretes (FIB, 2007).

Thermal diffusivity of concrete is influenced by type of aggregate and moisture content of the concrete. The mineralogical character of the aggregate used in a particular concrete has a significant effect on the conductivity and in turn diffusivity. As diffusivity is a function of conductivity it is similarly affected by moisture content, which depends on the original water content of the mix, degree of hydration of cement, and exposure to drying.

\section{Overview}

The experimental programme comprised the exposure of concrete panels $150 \mathrm{~mm}$ thick, with thermocouples embedded at varying depths, to elevated temperatures and recording over time the temperature at various locations within the concrete panels and of the kiln atmosphere. The temperature was increased to approximately $1100^{\circ} \mathrm{C}$ over a period of 4 hours. Temperature-time profiles were thereby constructed for various points in the samples. This allowed comparative studies of the performance of concretes with and without GGBS. The experimental data was modelled by a simplified version of the Hertz (2002) method and Wickström (1986) formula to allow quantification of the relative differences between the mixes.

\section{Specimen Preparation}

Four mixes were prepared, with limestone ('L') and sandstone ('S') coarse aggregates, either with no cement replacement ('GO') or with 70\% GGBS ('G7'). A summary of the mix proportions (designated 
LG0, LG7, SG0, SG7) and compressive strength values (28 days and 150 days - the day of heating) is given in Table 2. Aggregate properties are given in Table 3. The chemical composition (\%) of the GGBS was as follows:

$\begin{array}{ll}\mathrm{SiO}_{2} & 35.32 \% \\ \mathrm{Al}_{2} \mathrm{O}_{3} & 11.36 \% \\ \mathrm{Fe}_{2} \mathrm{O}_{3} & 0.58 \% \\ \mathrm{CaO} & 41.58 \% \\ \mathrm{MgO} & 7.69 \% \\ \mathrm{SO}_{3} & - \\ \mathrm{Na}_{2} \mathrm{O} & 0.27 \% \\ \mathrm{~K}_{2} \mathrm{O} & 0.4 \% \\ \mathrm{Cl}^{-} & 0.01 \%\end{array}$

Loss of Ignition $\quad 0.65 \%$ Insoluble Material $0.25 \%$

The cube specimens, which were $100 x$ $100 \times 100 \mathrm{~mm}$ in size were made and cured in accordance with I.S. EN 123902. The compressive strength tests were conducted in accordance with I.S. EN 12390-3. The concrete test panels for the experimental programme were $425 \mathrm{~mm} \times 425 \mathrm{~mm} \times 150 \mathrm{~mm}$ thick. Thermocouples were fixed centrally on plan and at depths of $37.5 \mathrm{~mm}, 75 \mathrm{~mm}$ and $112.5 \mathrm{~mm}$. Each batch of concrete allowed for the manufacture of a single test panel and four test cubes. Two batches were prepared per mix.

The concrete was carefully placed in layers so as not to dislodge or damage the thermocouples. The concrete was then compacted using a standard industry poker vibrator with care again being exercised not to disturb or damage the thermocouples. The top surface was levelled and finished smooth. The panels (Figure 4) were stored for three days and protected against shock, vibration and dehydration at a temperature of $20( \pm 5)^{\circ} \mathrm{C}$. After three days the panels were removed from the moulds and placed in storage under laboratory conditions until required for testing.

\begin{tabular}{l|c|c|c|c}
\hline \multirow{2}{*}{} & \multicolumn{4}{|c}{ Mix Designation and Constituents } \\
\cline { 2 - 5 } & Limestone Agg. & \multicolumn{2}{c}{ Sandstone Agg. } \\
\cline { 2 - 5 } & $\begin{array}{c}\text { LGO } \\
\left(\mathrm{kg} / \mathrm{m}^{3}\right)\end{array}$ & $\begin{array}{c}\text { LG7 } \\
\left(\mathrm{kg} / \mathrm{m}^{3}\right)\end{array}$ & $\begin{array}{c}\mathrm{SGO} \\
\left(\mathrm{kg} / \mathrm{m}^{3}\right)\end{array}$ & $\begin{array}{c}\mathrm{SG} 7 \\
\left(\mathrm{~kg} / \mathrm{m}^{3}\right)\end{array}$ \\
\hline CEM II/A-L & 320 & 96 & 320 & 96 \\
GGBS & 0 & 224 & 0 & 224 \\
Water & 175 & 175 & 175 & 175 \\
20mm Aggregate & 755 & 745 & 650 & 645 \\
10mm Aggregate & 470 & 465 & 535 & 535 \\
Sand & 640 & 635 & 655 & 650 \\
Total binder content & 320 & 320 & 320 & 320 \\
\hline W/b Ratio & 0.55 & 0.55 & 0.55 & 0.55 \\
\hline Compressive & & & & \\
strength at 28 days & $53 \mathrm{MPa}$ & $42 \mathrm{MPa}$ & $48 \mathrm{MPa}$ & $38 \mathrm{MPa}$ \\
Compressive & $60 \mathrm{MPa}$ & $50 \mathrm{MPa}$ & $57 \mathrm{MPa}$ & $47 \mathrm{MPa}$ \\
strength at 150 days & & & & \\
\hline
\end{tabular}

Table 2

Mix Proportions

\begin{tabular}{l|c|c|c}
\hline \multicolumn{1}{c|}{ Type } & $\begin{array}{c}\text { I.S. EN } \\
12620 \\
\text { Designation }\end{array}$ & $\begin{array}{c}\text { Water } \\
\text { Absorption } \\
\%\end{array}$ & $\begin{array}{c}\text { Density } \\
\left(\mathrm{kg} / \mathrm{m}^{3}\right)\end{array}$ \\
\hline Coarse Aggregate & & & \\
$20 \mathrm{~mm}$ Limestone & $10 / 20$ & 0.5 & 2,660 \\
$10 \mathrm{~mm}$ Limestone & $10 / 20$ & 0.7 & 2,660 \\
$20 \mathrm{~mm}$ Sandstone & $4 / 10$ & 1.8 & 2,620 \\
$10 \mathrm{~mm}$ Sandstone & $4 / 10$ & 2.0 & 2,620 \\
\hline Fine Aggregate & & & \\
Sand & $0 / 4$ & 2.0 & 2,580 \\
\hline
\end{tabular}

Table 3

Aggregate Properties

Fig. 4

Typical concrete panel specimen with label 
Fig. 5

Cross-section of kiln with concrete test panel in place

Fig. 6

Cross-sectional locations of thermocouples

Fig. 7

Plan locations of thermocouples

Fig. 8

Comparison of Standard and Parametric Fire Curves with Experimental Heat Regime
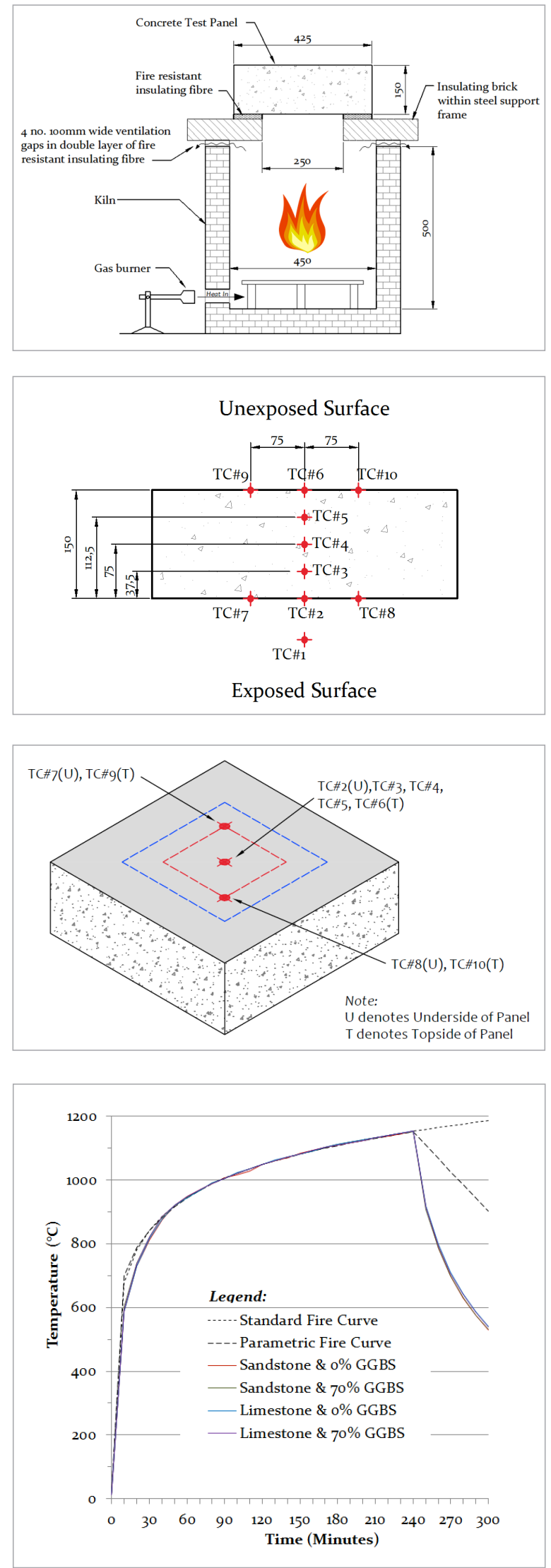

\section{Experimental Set-up}

Based on the approach of Mydin (2010), the set-up for the experiment is shown in Figure 5. A specially manufactured cover was constructed of insulating materials in order to create a $250 \mathrm{~mm}$ square opening at the top of the kiln. The concrete test panel was then placed over the opening and supported on a separate steel frame. The $250 \mathrm{~mm}$ square opening allowed for the concrete test panel to be heated from the underside. The kiln temperature was increased to approximately $1100^{\circ} \mathrm{C}$ over a period of 4 hours.

The development of higher temperatures through the panel cross section over time was measured with five Type $\mathrm{K}$ thermocouples (i.e. TC\#2-TC\#6), placed within the concrete panel at regular depths during casting. In order to verify that the heat transfer was unidirectional, four thermocouples (i.e. TC\#7TC\#10) were fixed at two corners of a $150 \mathrm{~mm}$ square positioned centrally on the specimen. One thermocouple (i.e. TC\#1) was placed $50 \mathrm{~mm}$ below the bottom surface of the test panel within the kiln to record the atmosphere temperature. Each Type $\mathrm{K}$ thermocouple was connected to an individual data logger which automatically recorded temperature readings at 30 second intervals. The locations of the thermocouples were as illustrated in Figure 6 and Figure 7. Unidirectional flow was confirmed as temperature differentials across all panels were reviewed after test and found to be consistent.

\section{Heating and cooling regime}

Standard fire curves allow classification of building materials and elements where the results are comparative and not project specific. The heating regime was largely in accordance with the standard curve as defined in Code I.S. EN 1991-1-2.

During the heating phase the achieved temperature profile resembled closely 
that of the standard fire curve. The furnace gas temperatures recorded during the experimental programme are illustrated in Figure 8, with the standard fire curve and a parametric fire curve included for comparison purposes. A parametric fire curve takes into account the compartment size, fuel load, ventilation conditions and the thermal properties of compartment walls and ceilings. Parametric fire curves provide more realistic estimates of the fire severity, for a given

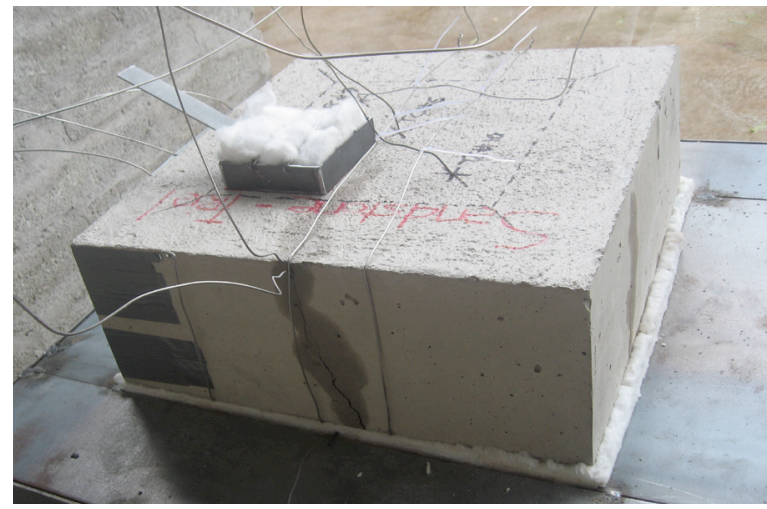
compartment, compared to the standard fire curves. The fire resistance time in terms of integrity (E) and insulation (I) is 3 hours for a $150 \mathrm{~mm}$ thick slab when using the tabulated method outlined in I.S. EN 1992-1-2. As this is considered conservative, the duration of the heating phase was 4 hours. On completion of the heat regime the panels were allowed to cool naturally on the test frame. The actual cooling profile was as shown in Figure 8.

\section{Assessment of Integrity Function (E)}

In line with requirements of I.S. EN 1363-1, the integrity of the panel was assessed throughout the heating regime by a cotton wool pad (Figure 9) and by monitoring the test specimens for gaps and sustained flaming.

\section{Assessment of Insulation Function (I)}

The insulation of the panel was assessed throughout the heat regime by monitoring and recording temperature at three locations on the unexposed surface of the test panel. Three Type $\mathrm{K}$ thermocouples were positioned on the unexposed surface as shown in Figure 9. While these thermocouple types are not exactly as specified in I.S. EN 1363-1, they were considered fit for purpose.

\section{Influence of Binder Type}

When the results for respective binder types are compared by averaging the results for the two aggregate types, the heat transfer is as illustrated in Figure 10. The temperature profile for concrete containing 70\% GGBS was lower than that of concrete with no GGBS (CEM II/ $A-L$ only). This was also the case when comparing binder influence for the mixes based on the two aggregate types.

When the results for respective aggregate types are compared irrespective of binder type, the heat transfer is as illustrated in Figure 11. While initially the temperature rise in the limestone aggregate is higher, with time the sandstone aggregate results in a higher temperature profile, which would be expected.

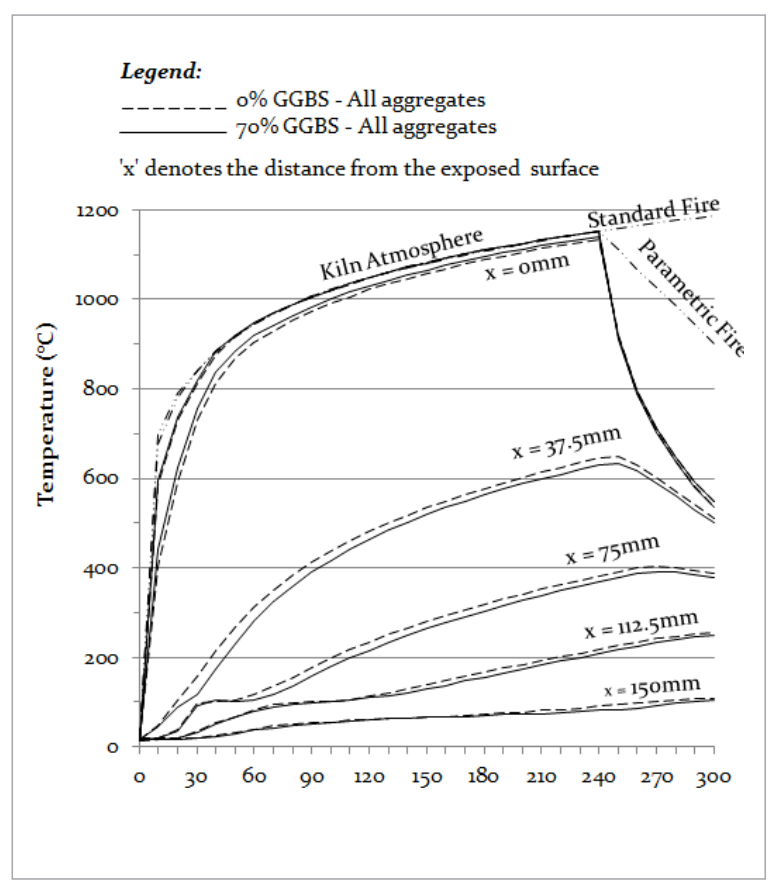

Fig. 9

Cotton pad on test specimen

\section{Results}

Fig. 10

Comparison of heat transfer based on binder type 
Fig. 11

Comparison of heat transfer based on aggregate type

Table 4

Critical Temperatures on Unexposed Surface

Fig. 12

Assessment of Insulation (I) criteria based on binder type

Table 5

Time to Critical Temperatures on Unexposed

Surface

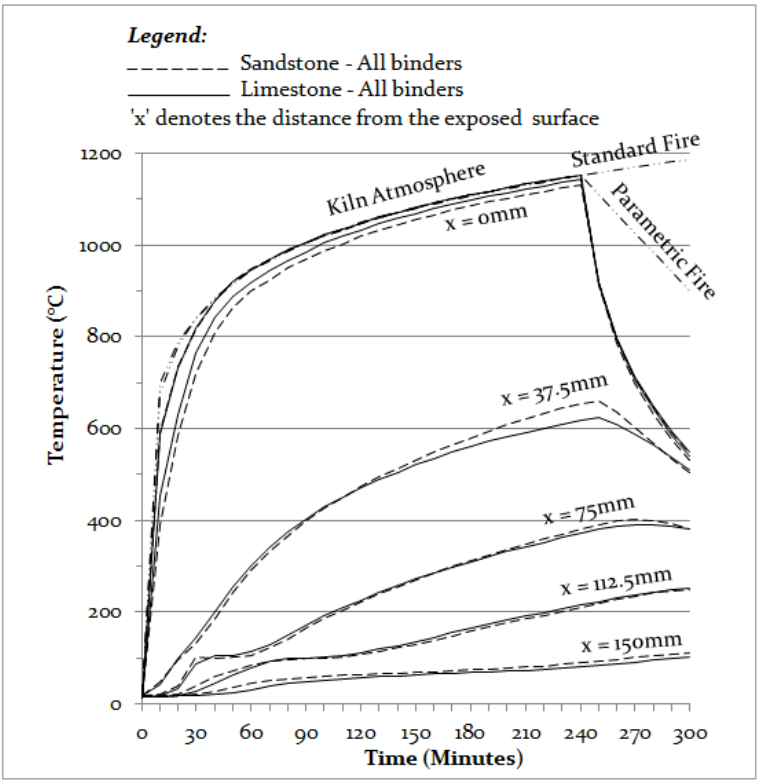

\begin{tabular}{c|c}
\hline Specimen ID & Temperature at 4 hours \\
\hline SGO & $106^{\circ} \mathrm{C}$ \\
\hline SG7 & $85^{\circ} \mathrm{C}$ \\
\hline LGO & $87^{\circ} \mathrm{C}$ \\
\hline LG7 & $79^{\circ} \mathrm{C}$ \\
\hline
\end{tabular}

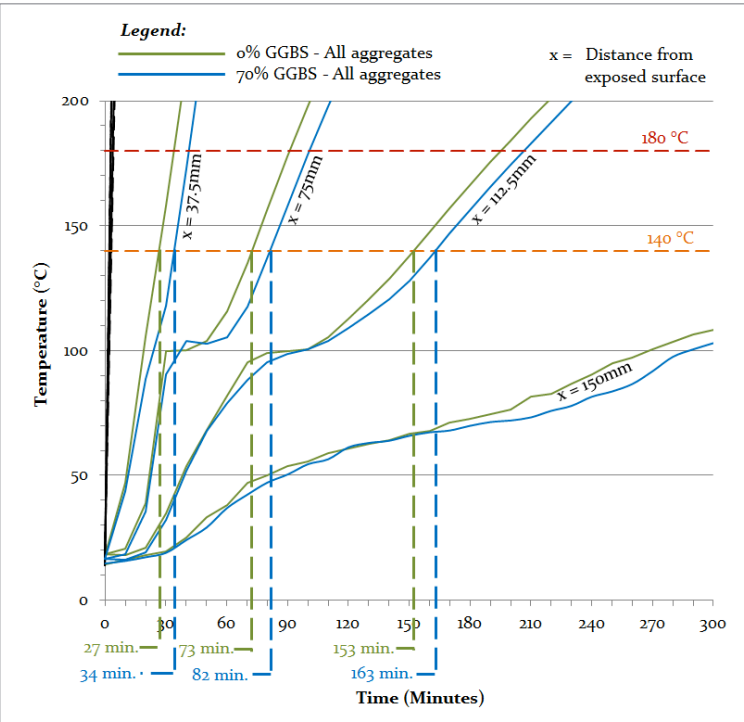

INTEGRITY FUNCTION (E)

The integrity of the panel was assessed throughout the heat regime. A cotton wool pad was placed on the panel and did not display any evidence of flaming. The test specimens were also monitored for gaps and sustained flaming, neither of which occurred during the heating regime.

\section{INSULATION FUNCTION (I)}

The average maximum temperature observed on the unexposed surface for respective mix types is given Table 4, none of which exceeded either the maximum allowable average of $140^{\circ} \mathrm{C}$ or maximum single temperature of $180^{\circ} \mathrm{C}$, as set out in I.S. EN 1363 (NSAI, 2012).

It was noted that the temperature on the unexposed side continued to increase after the heat regime was terminated. The maximum temperature on the unexposed side was generally observed between 90 and 120 minutes after termination of heat supply.

To eliminate the influence of external atmospheric temperatures (which varied from a low of $5^{\circ} \mathrm{C}$ to a high of $13^{\circ} \mathrm{C}$ over the duration of the test programme), the temperatures within the test specimens were considered in terms of Insulation (I) performance. The influence of binder type on performance is illustrated in Figure 12. The time taken to reach the maximum average temperature of $140^{\circ} \mathrm{C}$ at various distances from the exposed surface is given in Table 5 .

\begin{tabular}{c|c|c|c}
\hline \multirow{2}{*}{ Binder Type } & \multicolumn{3}{|c}{ Distance from Exposed Surface } \\
\cline { 2 - 4 } & $37.5 \mathrm{~mm}$ & $75 \mathrm{~mm}$ & $112.5 \mathrm{~mm}$ \\
\hline $100 \%$ CEM II; 0\% GGBS & 27 minutes & 73 minutes & 153 minutes \\
\hline $30 \%$ CEM II; 70\% GGBS & 34 minutes & 82 minutes & 163 minutes \\
\hline
\end{tabular}




\section{Heat Transfer}

The experimental data are displayed in the form of temperature profiles as published in current design codes in Figure 13. These profiles chart the variation in temperature with distance from the face of the concrete element for various times of fire exposure (e.g. 'R240' provided in the legend denotes 240 minutes exposure to standard fire conditions).

In terms of temperature profiles for concrete sections published in current design codes, the most applicable to this research is the profile relating to slabs published in I.S. EN 1992-1-2 (NSAl, 2005). Results show a good degree of consistency with I.S. EN 1992-1-2. Comparison of test data for concrete consisting of 70\% GGBS (i.e results are calculated by averaging the results for the two aggregate types) are illustrated in Figure 14. Comparison of test data for concrete consisting of $0 \%$ GGBS is as illustrated in Figure 15.

In both of the cases illustrated in Figures 14 and 15, the profiles are comparable with existing I.S. EN 1992-1-2 design charts. The test data profiles consistently indicate lower temperature across a member section than the relevant profiles in I.S. EN 1992-1-2. The profiles for $70 \%$ GGBS offer the optimum performance as the curves provide the lowest temperature profile across the section.

Following a comparison of experimental results for heat transfer with various published simplified formula methods, it is clear that the results compare well with those of Hertz (2002). A modified version of the Hertz simple formula was developed by varying the mathematical constants to better represent current research data, which offers a reasonable best-fit for modelling the test data. The proposed solution is only valid for standard fire exposure; however, it does allow for variation in thermal diffusivity, which is a function of density, specific heat capacity and thermal conductivity of the concrete as measured at ambient temperature.

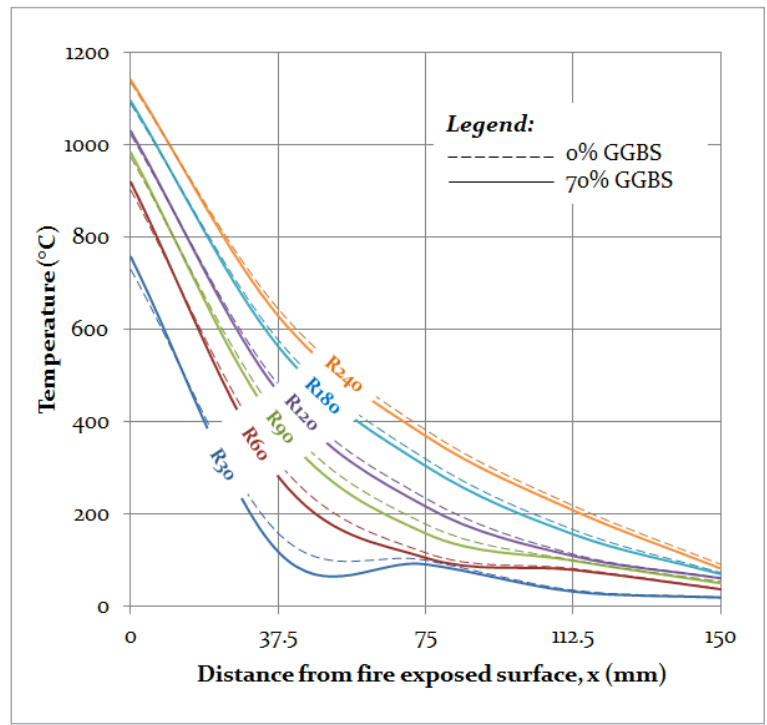

Discussion

Fig. 13

Comparison of temperature profiles for concrete panels of varying binder type and for varying fire exposure times (e.g. R240 represents 240 minutes of exposure to standard fire conditions)

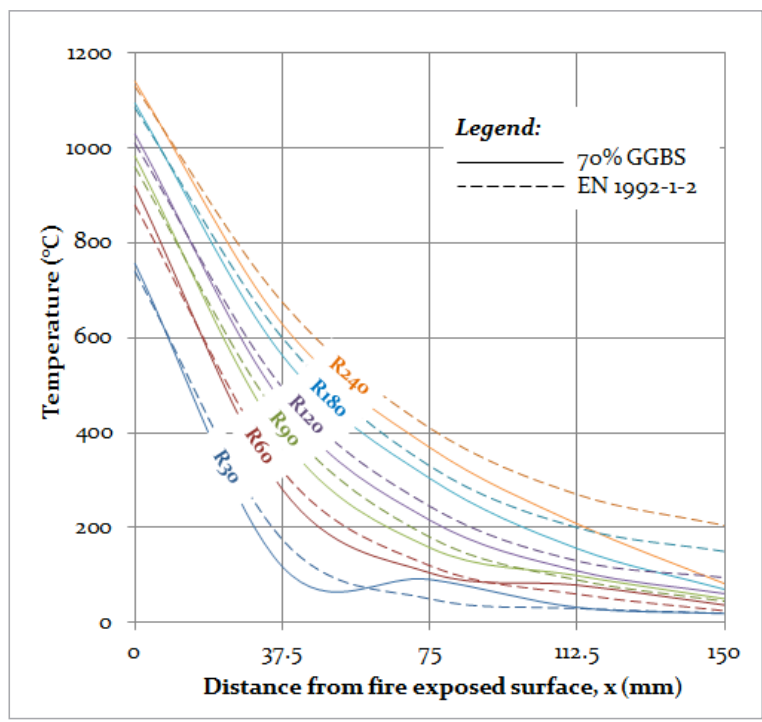

Fig. 14

Comparison of temperature profiles for $70 \%$ GGBS concrete test panels with I.S. EN 19921-2 profiles for varying fire exposure times (e.g. R240 represents 240 minutes of exposure to standard fire conditions)

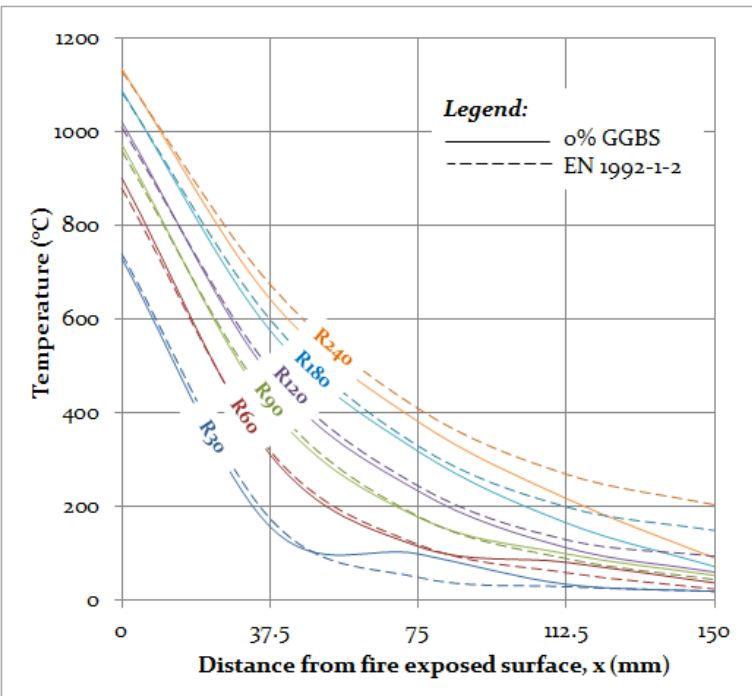

Fig. 15

Comparison of temperature profiles for 0\% GGBS concrete test panels with I.S. EN 19921-2 profiles for varying fire exposure times (e.g. R240 represents 240 minutes of exposure to standard fire conditions) 
The temperature $\left(T_{1}\right)$ within a concrete element at depth, $x$, from the fire exposed surface and at time, $\mathrm{t}$, is determined from Equation 2:

$t$ is time from ignition of the fire (i.e. fire duration) [min];

$\mathrm{x}$ is distance from the fire exposed surface of the concrete to the point under consideration within the section $[\mathrm{m}]$;

$\rho$ is density of concrete at elevated temperatures $\left[\mathrm{kg} / \mathrm{m}^{3}\right]$;

$\alpha$ is thermal diffusivity of concrete at elevated temperatures $\left[\mathrm{m}^{2} / \mathrm{s}\right]$;

$\lambda$ is thermal conductivity of concrete at elevated temperatures [W/m K];

$c_{p}$ is specific heat capacity of concrete at elevated temperatures $[\mathrm{J} / \mathrm{kg} \mathrm{K}$.
$\mathrm{T}_{1}(\mathrm{x}, \mathrm{t})=340 \cdot \log (8 \mathrm{t}+1) \cdot \exp (-2.25 \cdot \mathrm{k}(\mathrm{t}) \cdot \mathrm{x}) \cdot \sin (\pi / 2-\mathrm{k}(\mathrm{t}) \cdot \mathrm{x})$

where:

$$
\alpha(t)=\frac{\left(\frac{\pi}{750 \cdot \alpha \cdot t}\right)^{0.5}}{\rho \cdot c_{p}}
$$

Equation 2 is valid when the following conditions apply:

$$
\mathrm{T}_{1}(\mathrm{x}, \mathrm{t}) \geq 20 \quad \text { and } \quad \mathrm{x} \quad<\frac{\pi}{2 \cdot \mathrm{k}(\mathrm{t})}
$$

Otherwise, $\mathrm{T}_{1}(\mathrm{x}, \mathrm{t})=20$.
Fig. 16

Comparison of modified formula representative of $0 \%$ GGBS concrete and experimental data from present investigations

\section{Fig. 17}

Comparison of modified formula representative of $70 \%$ GGBS concrete and experimental data from present investigations
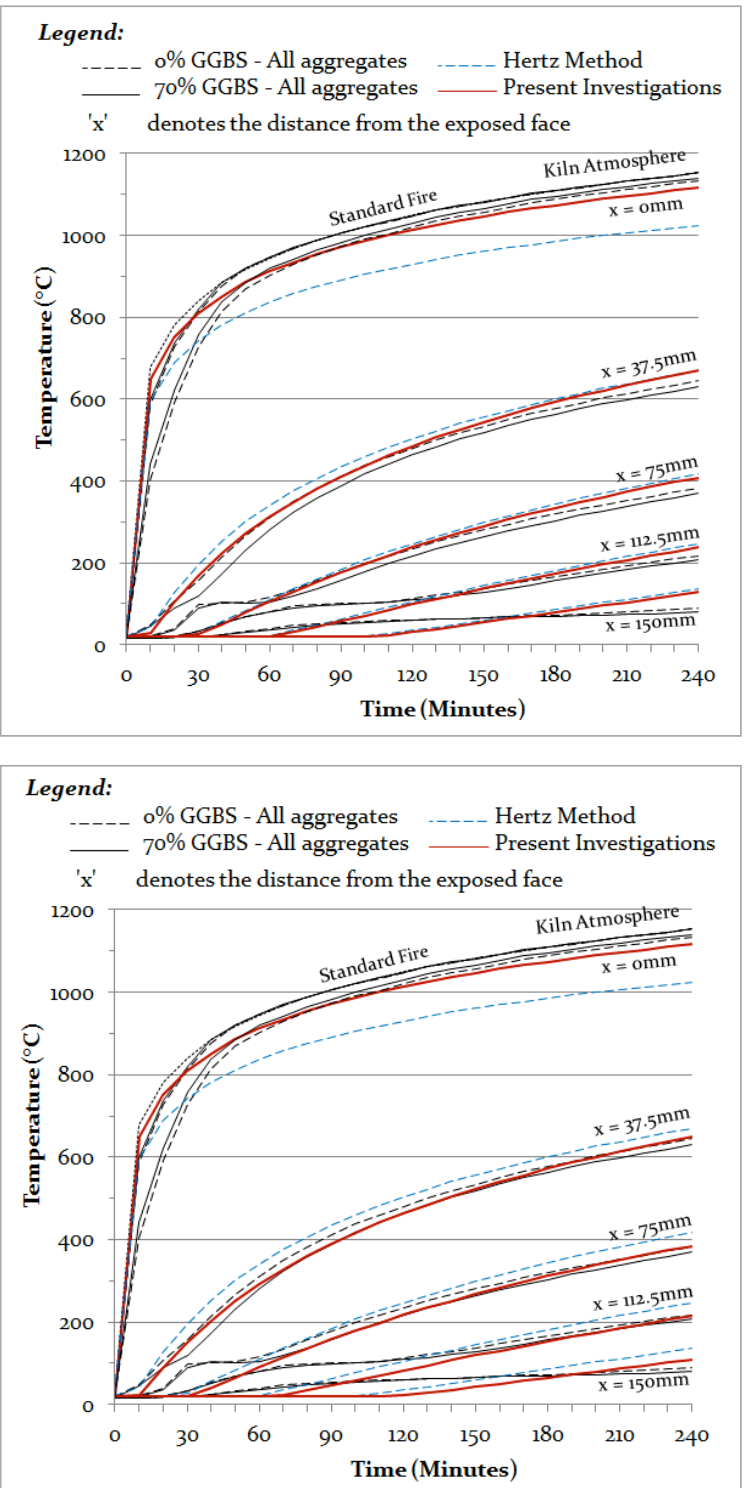

In order to replicate the lower thermal profile for concrete containing 70\% GGBS, the thermal diffusivity may be varied. The thermal diffusivity for the concrete containing 0\% GGBS was $0.523 \mathrm{~mm}^{2} / \mathrm{s}$. For the concrete containing 70\% GGBS the thermal diffusivity was $0.468 \mathrm{~mm}^{2} / \mathrm{s}$. The time-temperature profiles at varying depths from the exposed surface based on the proposed formula and the experimental data are illustrated in Figures 16 and 17 for concrete with $0 \%$ and $70 \%$ GGBS respectively. Adopting the average density for respective mix types and assuming the specific heat as equal, the thermal conductivities of the concretes would be $1.264 \mathrm{~W} / \mathrm{mK}$ and $1.11 \mathrm{~W} / \mathrm{mK}$ for concrete containing 0\% GGBS and 70\% GGBS respectively. Such a difference in thermal conductivity values is comparable with the findings of Demirboga et al (2007).

\section{Assessment of Performance - El INTEGRITY FUNCTION (E)}

The criteria for assessing the integrity function of a separating element are outlined in I.S. EN 1363 (NSAI, 2012). Such criteria were considered during the experimental programme and were found to be satisfied for a $150 \mathrm{~mm}$ concrete panel after a four hour heat regime. 


\section{INSULATION FUNCTION (I)}

The insulation function (I) was assessed in accordance with I.S. EN 1365 by monitoring the surface temperature on the unexposed face of the concrete. This requires that the average temperature across the area should not exceed $140^{\circ} \mathrm{C}$, while the temperature at any single point should not exceed $180^{\circ} \mathrm{C}$. The minimum dimensions for particular fire resistance periods as specified in I.S. EN1992-1-2 (NSAl, 2005) for both slabs and non-loadbearing walls are given in Table 6.

\begin{tabular}{|c|c|c|c|c|c|c|c|}
\hline \multirow{2}{*}{ Element } & \multirow{2}{*}{ 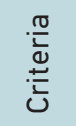 } & \multicolumn{6}{|c|}{ Distance from Exposed Surface } \\
\hline & & 30 & 60 & 90 & 120 & 180 & 240 \\
\hline Slab & $\mathrm{REI}^{1}$ & $60 \mathrm{~mm}$ & $80 \mathrm{~mm}$ & $100 \mathrm{~mm}$ & $120 \mathrm{~mm}$ & $150 \mathrm{~mm}$ & $175 \mathrm{~mm}$ \\
\hline $\begin{array}{l}\text { Non-load } \\
\text { bearing Wall }\end{array}$ & $\mathrm{El}^{2}$ & $60 \mathrm{~mm}$ & $80 \mathrm{~mm}$ & $100 \mathrm{~mm}$ & $120 \mathrm{~mm}$ & $150 \mathrm{~mm}$ & $175 \mathrm{~mm}$ \\
\hline
\end{tabular}

Note $\quad{ }^{1}$ REl criteria address resistance, integrity and insulation requirements as outlined in Section 1.2.

${ }^{2}$ El criteria address integrity and insulation requirements as outlined in Section 1.2.

If existing simple formulae for heat transfer are now considered in conjunction with Eurocode minimum thicknesses, some notable outcomes are apparent. The Wickström formula (Wickstrom, 1986) is the most widely used and referenced of the simple formulae, while the Hertz (2002) method showed good correlation with experimental data. The unexposed surface temperature was calculated for the minimum slab thicknesses and times specified in Table 6 using the Wickström formula, the Hertz formula, and the modified formula, which represents current experimental data. The results of such calculations are illustrated in Figure 18.

In the case of Wickström and Hertz, the unexposed surface temperatures vary for fire resistance periods of 30, 60 and 90 minutes and the temperature appears to be consistent at approximately $75^{\circ} \mathrm{C}$ thereafter. It is worth noting that the temperature of $75^{\circ} \mathrm{C}$ is extremely conservative when the I.S. EN 1365 maximum average of $140^{\circ} \mathrm{C}$ is considered. The recommended maximum value of Babrauskas is $400^{\circ} \mathrm{C}$, which is over $300^{\circ} \mathrm{C}$ greater than the calculated value (Babrauskas, 2007).

If $75^{\circ} \mathrm{C}$ was considered the desirable value for the temperature of the unexposed face then the minimum thickness of the element required, calculated using

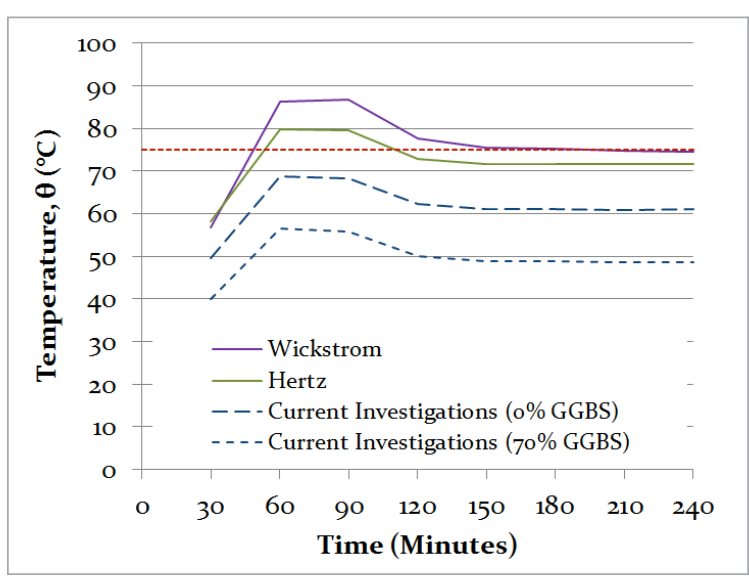

Fig. 18

Calculated temperatures for the minimum thicknesses and times specified in Table 6

Fig. 19

Calculated minimum thicknesses required to maintain the unexposed surface at a temperature of $75^{\circ} \mathrm{C}$ and $140^{\circ} \mathrm{C}$ for varying duration of exposure to fire 
formula by Wickström, Hertz and formulae representing current investigations, are illustrated in Figure 19. This also shows values for thickness if the criterion for maximum unexposed face temperature was $140^{\circ} \mathrm{C}$.

This is evidence that the reduced heat transfer of the concrete with 70\% GGBS identified in this research results in reduced minimum section requirements. For example for a fire resistance period of 240 minutes the minimum thickness is reduced from $175 \mathrm{~mm}$ to $153 \mathrm{~mm}$. On a large scale project this could result in large scale cost savings as well as environmental benefits.

The foregoing assessment indicates that the minimum thicknesses specified in I.S. EN 1992-1-2 are extremely conservative as illustrated in Figure 19. It should be noted that the minimum thicknesses as required by I.S. EN 1992-1-2 may exist to satisfy the integrity function (E); however, this is not clear from the document.

In the case of the separating function (EI) tests, the panels were monitored for a period of time after heat regime. Immediately after heating and subsequent cooling the exposed surface displayed extensive hairline surface cracking. Rehydration resulted in deterioration of the concrete near the surface.

\section{Structural Design Approach}

The experimental programme considered two aspects of concrete in fire which are fundamental to structural fire deign, namely the compressive strength and rate of heat transfer. Following a review of the experimental outcomes, a relatively small but consistent difference in heat transfer was identified as illustrated in Figure 10. Consequently, this data was adopted for the design of a $150 \mathrm{~mm}$ thick reinforced concrete slab in accordance with I.S. EN 1992-1-2 to establish the influence of such a difference on the structural design.

A summary of the design outcomes is presented in Table 7, where $M_{E d, f}$ is the applied moment from the effect of actions on the slab, $M_{R d, f}$ is the design resistance moment and the utilisation

\begin{tabular}{|c|c|c|c|c|c|c|c|c|}
\hline \multirow{8}{*}{$\begin{array}{r}\text { Summary of design } \\
\text { calculations }\end{array}$} & & Fire Resistance & $R_{30}$ & R6o & R9o & R120 & R18o & $R_{240}$ \\
\hline & & $\mathrm{M}_{\mathrm{Ed}, \mathrm{fi}}[\mathrm{kNm}]$ & 26.2 & 26.2 & 26.2 & 26.2 & 26.2 & 26.2 \\
\hline & \multirow{2}{*}{$\begin{array}{l}\text { I.S. EN 1992-1-2 Figure } \\
\text { A.2 }\end{array}$} & $\mathrm{M}_{\mathrm{Rd}, \mathrm{f}[}[\mathrm{kNm}]$ & 44.0 & 39.8 & 28.8 & 19.6 & 9.7 & 6.0 \\
\hline & & Utilisation Ratio & 0.60 & 0.66 & 0.91 & 1.34 & 2.70 & 4.35 \\
\hline & \multirow{2}{*}{$\begin{array}{l}\text { Exp. Data for o\% GGBS } \\
\text { Concrete }\end{array}$} & $\mathrm{M}_{\mathrm{Rd}, \mathrm{fi}}[\mathrm{kNm}]$ & 44.0 & 38.6 & 26.6 & 18.7 & 10.1 & 6.9 \\
\hline & & Utilisation Ratio & 0.60 & 0.68 & 0.98 & 1.40 & 2.58 & 3.77 \\
\hline & \multirow{2}{*}{$\begin{array}{l}\text { Exp. Data for } 70 \% \text { GGBS } \\
\text { Concrete }\end{array}$} & $\mathrm{M}_{\mathrm{Rd}, \mathrm{f}}[\mathrm{kNm}]$ & 44.0 & 40.6 & 29.2 & 20.5 & 11.1 & 7.4 \\
\hline & & Utilisation Ratio & 0.60 & 0.64 & 0.90 & 1.28 & 2.37 & 3.54 \\
\hline
\end{tabular}

Fig. 20

Comparison of resistance moments for varying reference data

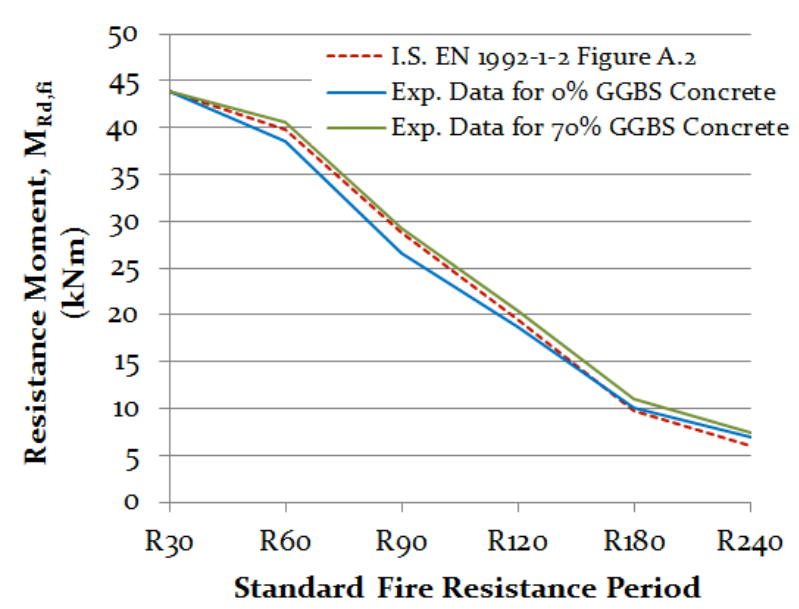

ratio is the ratio of $M_{E d, f i}$ to $M_{\text {Rdff. }}$. The calculations were completed for each of the standard fire resistance periods from R30 to R240. The design calculations were first completed using data exclusively from I.S. EN 1992-1-2, and then repeated with experimental data from Figure 13 replacing data from Figure A.2 of I.S. EN 1992-12. The resistance moments for respective reference data are illustrated in Figure 20 , where the concrete with $70 \%$ GGBS performs better than the I.S. EN 1992-1-2 data while the concrete with $0 \%$ GGBS performs below that of the I.S. EN 1992-1-2 data.

The moment of resistance for fire resistance period 
R240 in Table 7 is for illustrative purposes only as the strain in the steel is excessive indicating that the stress in the steel has to be reduced in accordance with I.S. EN 1992-1-1. However, in the calculations no reduction in the steel stress is included in the calculation of the moment of resistance of the section. Moreover, a $150 \mathrm{~mm}$ slab does not meet the minimum thickness requirements for an REI240 fire resistance period. This is restricted in accordance with Table 5.8 of I.S. EN 1992-1-2 to an REI180 fire resistance period.

When the tabulated method in accordance with I.S. EN 1992-1-2 is applied to the design example, the fire resistance period is limited to REI60, as the period of fire resistance for standard fire conditions is 78 minutes when derived by interpolation from Table 5.8 of I.S. EN 1992-1-2. However, when the ' $500^{\circ} \mathrm{C}$ isotherm' simplified method is used, a fire resistance period of REI90 is possible. Hence, the use of such calculation methods can result in more sustainable and economic design outcomes. In addition, the inclusion of GGBS as a binder replacement results in a 5\% to $10 \%$ increase in the moment of resistance for fire resistance periods including and above REI60 as illustrated in Figure 20.

The aim of this research was to establish whether the use of Ground Granulated Blastfurnace Slag (GGBS) as a binder replacement in concrete influences performance at elevated temperatures in the context of fire resistance. The marginally lower transfer of heat exhibited by GGBS concrete improves performance in terms the separating function and could allow a $5 \%$ reduction in the thickness of reinforced concrete separating elements. In addition, increased resistance to the effects of actions on a member, designed in accordance with the $500^{\circ} \mathrm{C}$ isotherm 'simplified' method detailed in I.S. EN 1992-1-2 (NSAl, 2005), are also possible with increased resistance of up to $10 \%$.

Heat transfer, and more specifically thermal conductivity, is a function of the density, specific heat, and thermal diffusivity of the concrete. The density and compressive strength of the GGBS concrete was lower than that of the concrete containing only CEM II/A-L at the time of testing. It is postulated that the lower density of the GGBS concrete results in a reduction in the associated thermal conductivity, hence its improved performance in terms of heat transfer. A significant obstacle encountered during this research was the lack of clear and established practice in determining the thermal properties of concrete. Reported research is not prevalent, and is often dated, for thermal properties at ambient temperature and is even less prevalent at elevated temperatures. Recently established techniques include the Transient Plane Source (TPS) method which may be used to determine the various thermal properties at both ambient and elevated temperatures. However, the apparatus to complete this type of test is expensive and not widely available. A method of determining the thermal properties of concrete which is both accurate and economic should be established for testing concrete at both ambient and elevated temperatures.

Ecocem Ireland Ltd. is acknowledged for the supply of binder materials used in the manufacture of test specimens.

\section{Conclusions}

Aßbrock O., Brameshuber, W. \& Droll, D. 2007. Ground Granulated Blastfurnace Slag (GGBS) as a concrete additive - Current situation and scenarios for its use in Germany. Verein Deutscher Zementwerke, Düsseldorf, $135 \mathrm{pp}$.

Babraskas V. 2007. Unexposed-face temperature criteria in fire resistance tests: A reappraisal. Fire and Materials 2007 - $10^{\text {th }}$ International Conference and Exhibition. San Francisco, USA.
Bamonte, P., Gambarova, P. G. \& Meda, A. 2008. Today's concretes exposed to fire - test results and sectional analysis. Structural Concrete [Online], 9. Available: http://www.icevirtuallibrary.com/content/ article/10.1680/stco.2008.9.1.19.

http://dx.doi.org/10.1680/stco.2008.9.1.19

Demirboga, R. 2007. Thermal conductivity and compressive strength of concrete incorporation with mineral admixtures. Building and Environment,
References 
42, 2467-2471. http://dx.doi.org/10.1016/j.buildenv. 2006.06 .010

Demirboga, R., Turkmen, I. \& Burhan Karakoc, M. 2007. Thermo-mechanical properties of concrete containing high-volume mineral admixtures. Building and Environment, 42, 349-354.

http://dx.doi.org/10.1016/j.buildenv.2005.08.027

FIB. 2007. Fire design of concrete structures - materials, structures and modelling, International Federation for Structural Concrete (FIB).

Harmathy, T. Z. 1970. Thermal properties of concrete at elevated temperatures. ASTM Journal of Materials, 47-74.

Hertz, K. 2002. Documentation for calculations of standard fire resistance of slabs and walls of concrete with expanded clay aggregate, Technical University of Denmark.

Khan, M. I. 2002. Factors affecting the thermal properties of concrete and applicability of its prediction models. Building and Environment, 37, 607-614. http://dx.doi.org/10.1016/S0360-1323(01)00061-0

Mydin, M. A. O. 2010. Lightweight foamed concrete (LFC) thermal and mechanical properties at elevated temperatures and its application to composite walling systems. Doctoral thesis, University of Manchester.

Neville, A. M. 1995. Properties of Concrete, Pearson Education Limited.

NSAI 2005 I.S. EN 1992-1-2:2005 Euro ode 2: Design of Concrete Structures - Part 1-2: General Rules - Structural Fire Design (including National Annex). National Standards Authority of Ireland.

NSAI 2012. I.S. EN 1363-1:2000 Fire Resistance Tests - General Requirements. National Standards Authority of Ireland (NSAI).

Wickstrom, U. 1986. A very simple method for estimating temperature in fire exposed concrete structures. Swedish Natiuonal Testing Institute.

\section{About the authors}

TED MCKENNA

BE MEngSc C.Eng MIEI

Lecturer at the Department of Civil, Structural and Environmental Engineering, Cork Institute of Technology

Main research area Concrete structures in fire, Building Information Modelling (BIM)

\section{Address}

Bishopstown, Cork, Ireland

Tel. +353 214335156

E-mail: ted.mckenna@cit.ie
MARK G. RICHARDSON

BE MEngSc PhD MICT C.Eng FIEI

Head of School, UCD School of Civil, Structural and Environmental Engineering, University College Dublin.

\section{Main research area}

Durability of reinforced concrete structures, especially related to carbonation and alkali-aggregate reaction

\section{Address}

University College Dublin, Belfield, Dublin 4, Ireland Tel. +353 17163255

E-mail: mark.richardson@ucd.ie

\section{BRIAN O'ROURKE}

BE MEngSc C.Eng MIEI

Lecturer at the Department of Civil, Structural and Environmental Engineering, Cork Institute of Technology

\section{Main research area}

Concrete durability, prestressed concrete

\section{Address}

Bishopstown, Cork, Ireland Tel. +353 214326485

E-mail: brian.orourke@cit.ie 